Farum

Sociológico

\section{Forum Sociológico}

Série II

$34 \mid 2019$

Habitação nas áreas urbanas de Lisboa e Porto: Da comunidade aos decisores políticos

\title{
Acesso à habitação por todos e para todos? Paradigmas e paradoxos da actualidade portuguesa
}

Access to housing by all and for all? Today's paradigms and paradoxes in Portugal

Sílvia Leiria Viegas

(2) OpenEdition

Journals

Edição electrónica

URL: https://journals.openedition.org/sociologico/4864

DOI: $10.4000 /$ sociologico.4864

ISSN: $2182-7427$

Editora

CICS.NOVA - Centro Interdisciplinar de Ciências Sociais da Universidade Nova de Lisboa

Edição impressa

Paginação: $71-80$

ISSN: 0872-8380

Refêrencia eletrónica

Sílvia Leiria Viegas, «Acesso à habitação por todos e para todos? Paradigmas e paradoxos da actualidade portuguesa», Forum Sociológico [Online], 34 | 2019, posto online no dia 19 agosto 2019, consultado o 29 março 2022. URL: http://journals.openedition.org/sociologico/4864 ; DOI: https:// doi.org/10.4000/sociologico.4864 


\title{
ACESSO À HABITAÇÃO POR TODOS E PARA TODOS? PARADIGMAS E PARADOXOS DA ACTUALIDADE PORTUGUESA
}

\section{ACCESS TO HOUSING BY ALL AND FOR ALL? TODAY'S PARADIGMS AND PARADOXES IN PORTUGAL}

\author{
Sílvia Leiria Viegas \\ Centro de Estudos Sociais da Universidade de Coimbra (CCArq/CES-UC) e Faculdade de Arquitectura da Universidade \\ de Lisboa (GESTUAL/FA-UL)
}

\begin{abstract}
Resumo
O artigo versa sobre o acesso à habitação condigna em Portugal na contemporaneidade, por populações de médios e poucos recursos, de diferentes origens culturais e/ou étnicas, tendo em conta a transformação da sociedade urbana em curso. Viso sistematizar paradigmas habitacionais dominantes e seus impactes excludentes, a par de resistências locais, e, ao mesmo tempo, reconhecer os paradoxos de inclusão-exclusão inerentes aos ensaios governamentais na forja, socioespaciais e habitacionais. Para o efeito, recorro ao pensamento estruturante de autores teóricos como Foucault, Žižek, Lefebvre e Harvey, e às suas ideias-chave de governamentalidade, tolerância multicultural e direito à cidade. Concluo apontando as contradições do sistema neoliberal dominante conformando, simultaneamente, exclusão e esperança.
\end{abstract}

Palavras-chave: acesso à habitação, governamentalidade, tolerância multicultural, direito à cidade

\begin{abstract}
The article deals with the access to adequate housing in Portugal at the present time, by middle and low income populations, of diverse cultural and/or ethnic origins, taking into account the ongoing transformation of the urban society. I aim to systematise the dominant housing paradigms and their excluding impacts, together with local resistances and, at the same time, to recognise inclusion-exclusion paradoxes intrinsic to the forging of new governmental socio-spatial and housing experiments. To that end, I turn to the structuring thoughts of theoretical authors such as Foucault, Žižek, Lefebvre and Harvey, and their key ideas of governamentality, multicultural tolerance, and the right to the city. To conclude, I point out the contradictions of the dominant neo-liberal system, simultaneously forming exclusion and hope.
\end{abstract}

Keywords: access to housing, governamentality, multicultural tolerance, right to the city

Este artigo surge no âmbito de um estudo individual mais extensivo onde viso identificar estratégias, políticas, práticas espaciais e espaços habitacionais inclusivos para refugiados e migrantes vulneráveis em Portugal na actualidade, em contexto neoliberal ${ }^{1}$. Como referência e controlo recorro, nessa pesquisa, ao mote da produção do espaço habitacional para migrantes vulneráveis vindos de países africanos de língua portuguesa, desde há cerca de 40 anos, e seus descendentes. É nos pontos de contacto esboçados entre a produção oficial, leia-se condutas públicas, e práticas quotidianas, que viso encontrar respostas mais favoráveis à melhoria da qualidade de vida urbana destas populações. Esta dinâmica é complexa e contempla as permeabilidades dos actores e a integração de novos hábitos e costumes, numa lógica de reciprocidade.

O foco desta reflexão é o acesso ao espaço e à habitação em geral. O intuito é perceber como ensaios abrangentes conduzidos pela Nova Geração 
de Políticas de Habitação, lançada em 2017, podem contribuir positivamente para a inclusão socioespacial e habitacional de refugiados e migrantes vulneráveis. Aqui coloco as seguintes questões: (1) Qual a margem de manobra da actual governação nacional para contrariar as linhas sistémicas excludentes da conjuntura neoliberal dominante? (2) Qual a capacidade, no curto período legislativo, de criar mecanismos de inclusão habitacional para os grupos sociais de médios e de poucos recursos com repercussão positiva a médio e longo prazo? (3) De que forma a discriminação do "outro", migrante, condiciona o seu acesso à habitação e ao espaço habitacional, mesmo em cenários ditos apontados para a igualdade socioespacial?

Metodologicamente, recorro à sistematização das acções e contra-acções forjadas em torno da promoção do acesso à habitação e seus principais intervenientes, dando particular atenção ao receituário governamental recém-ratificado e em discussão, procurando apurar se esse acesso à habitação é defendido e promovido por todos. Também identifico os exemplos de exclusão dominantes, especialmente na Área Metropolitana de Lisboa (AML), onde reside $27,5 \%$ da população de Portugal ${ }^{2}$. E destaco as contradições que o governo actual enfrenta nos alegados processos de inclusão socioespacial, procurando verificar se a defesa e a promoção do acesso à habitação em Portugal são dirigidas a todos. A reflexão estrutura-se no cruzamento deste duplo esclarecimento com o conceito norteador de direito à cidade, na acepção crítica de Lefebvre (2009). Outras noções teóricas como governamentalidade e tolerância multicultural, advogadas por Foucault (2008) e Žižek (1997), também são abordadas fixando a tónica no controlo e na exclusão.

\section{Acesso à habitação}

O corrente contexto governativo português ${ }^{3}$, favorável à produção de uma Nova Geração de Políticas de Habitação (SEH, 2017), sucede ao Verão charneira de 2015 que assinalou a chegada massiva de refugiados oriundos de África e do Médio Oriente à Europa. Por sua vez, 2018 configurou a meta proclamada pelo Estado português para o seu maior acolhimento, 10000 pessoas, no quadro da recente crise político-económica e migratória europeia ${ }^{4}$. Contudo, hoje, em Portugal, outros desafios relacionados com a inclusão se perfilam com mais expressão, sendo o acesso à habitação por grupos de médios e parcos recursos uma preocupação do executivo. Ao mesmo tempo, a sociedade civil tem apontado situações de discriminação e de xenofobia no exercício de vários direitos, como à habitação, relacionadas com questões como a origem, etnicidade e cor da pele ${ }^{5}$.

Relativamente ao acesso à habitação através do mercado, em 2017 o Instituto Nacional de Estatística destacou o preço médio de compra em Lisboa, 2231 $€ / \mathrm{m}^{2}$, por ser o mais alto de Portugal (INE, 2017a) ${ }^{6}$. Outra fonte (CI/SIR apud. Lisboa custa, em média, 3291 euros por metro quadrado, 2017) menciona valores mais expressivos, $3291 € / \mathrm{m}^{2}$, atirando freguesias centrais (Santo António, Misericórdia, Parque das Nações) para $5456 € / \mathrm{m}^{2}$. Nestes locais mais procurados, o Jornal de Negócios (Ledo, 2018) divulgou vendas na ordem dos $10000 € / \mathrm{m}^{2}$, próximo dos valores de capitais com economias fortes, como Paris. Sabendo que, nesse ano, em Portugal, cada família apresentou um rendimento médio/ano de $€ 31$ 390,50 (Pordata, s.d.b), com poupança bruta correspondente a 5,4\% dessa receita (Pordata, s.d.c), a maioria não consegue comprar casa sem pedir um empréstimo bancário, ficando assim sujeita às oscilações económicas e seus impactes na taxa de juro e na prestação mensal. Sublinho que a poupança média anual destas famílias é significativamente menor do que o menor preço médio por metro quadrado ultimamente praticado na venda de casa em Lisboa (Quadros 1 e 2).

Quadro $1 \triangleright$ Valor de compra das habitações em Lisboa

\begin{tabular}{c|c|l|c}
\cline { 2 - 4 } & \multicolumn{2}{|c|}{ Valor médio } & Valor excepcional \\
\hline Cidade & $2231 € / \mathrm{m}^{2 *}$ & $3291 € / \mathrm{m}^{2 * *}$ & - \\
\hline Centro & - & $5456 € / \mathrm{m}^{2}$ & $10000 € / \mathrm{m}^{2 * * *}$ \\
\hline
\end{tabular}

Fontes: *INE (2017a); **CI/SIR apud. Lisboa custa, em média, 3291 euros por metro quadrado, 2017; ***Ledo, 2018

Quadro $2 \triangleright$ Relação entre rendimento médio anual das famílias e poupança bruta

\begin{tabular}{c|c}
\hline Rendimento médio/ano & Poupança bruta/ano \\
\hline $100 \%$ & $5,4 \%$ \\
\hline$€ 31390,5$ & $€ 1695$ \\
\hline
\end{tabular}

Fonte: Pordata (s.d.a; s.d.b)

No que se refere às actuais situações de precariedade habitacional, após a auscultação dos municípios, o IHRU (2018, pp. 20-21) identificou 25762 famílias a necessitar de realojamento, encontrando-se a maioria nos distritos de Lisboa $(38,31 \%)$, Porto $(19,73 \%)$ e Setúbal $(16,15 \%)$. Mais de metade vive na AML $(54,46 \%)$ (Quadro 3). Juntando a Área Metropolitana do Porto (AMP), verificamos que quase três quartos das carências habitacionais em Portugal estão nas grandes cidades, corroborando a noção de que o magnetismo da urbanização prevalece em condições adversas. Sabemos, também, que nos distritos de Lisboa e Setúbal residem 209293 estrangeiros, 52,6\% dos 397731 cidadãos não portugueses com domicílio em Portugal (SEF, 2016, pp. 10-12) (Quadro 4). Os dados não contemplam os indivíduos que, entretanto, 
obtiveram nacionalidade portuguesa, sobretudo os africanos e seus descendentes, incluindo os de parcos recursos ${ }^{7}$. Porém, o levantamento habitacional do IHRU não relaciona os níveis de precariedade existentes com os contextos de origem, socioculturais e/ou étnicos dos sujeitos, e situações de discriminação ${ }^{8}$. Entretanto, estas existem e reproduzem-se no espaço habitacional que as denuncia, assumindo contornos próprios dentro do actual contexto dos paradigmas de exclusão socioespacial em Portugal. fundarei estas noções no ponto da reflexão cruzada sobre teorização dos factos.

\section{Paradigmas}

São três os exemplos de exclusão socioespacial e habitacional, de matriz neoliberal, que se destacam presentemente em Portugal, sobretudo na AML: (1) as práticas de renovação e reabilitação do centro urbano; (2) alguns realojamentos efectuados no

Quadro $3 \triangleright$ Necessidades de realojamento nas AML e AMP

\begin{tabular}{|c|c|c|c|c|}
\hline & \multicolumn{2}{|c|}{ AML } & \multirow{2}{*}{$\begin{array}{c}\text { AMP } \\
\text { Porto }\end{array}$} & \multirow[t]{2}{*}{ Total } \\
\hline & Lisboa & Setúbal & & \\
\hline \multirow{2}{*}{ Valores percentuais } & $38,31 \%$ & $16,15 \%$ & $19,73 \%$ & $100 \%$ \\
\hline & \multicolumn{2}{|c|}{$54,46 \%$} & & \\
\hline Valores absolutos & 9869 & 4161 & 5222 & 25762 \\
\hline
\end{tabular}

Fonte: IHRU (2018, pp. 20-21)

Quadro $4 \triangleright$ Cidadãos estrangeiros com domicílio na AML e Portugal

\begin{tabular}{|c|c|c|c|}
\hline & \multicolumn{2}{|c|}{ AML } & \multirow[t]{2}{*}{ Total } \\
\hline & Lisboa & Setúbal & \\
\hline \multirow{2}{*}{ Valores percentuais } & $43,53 \%$ & $9,10 \%$ & $100 \%$ \\
\hline & \multicolumn{2}{|c|}{$52,6 \%$} & \\
\hline \multirow{2}{*}{ Valores absolutos } & 173118 & 36175 & 397731 \\
\hline & \multicolumn{2}{|c|}{209293} & \\
\hline
\end{tabular}

Fonte: SEF (2016, pp. 10-12)

Lanço agora dois conceitos teóricos que se relacionam com o acesso à habitação em Portugal, ligados a questões de poder, neste caso económico, e a dinâmicas de racismo e xenofobia. Em 1977/78, Foucault (2008) discursou sobre a governamentalidade e a criação de mecanismos de alegada inclusão que, paradoxalmente, sustentam uma estrutura, per se, excludente; cerca de 20 anos depois, Žižek (1997) alertou sobre os perigos da tolerância multicultural que reforçam a discriminação pejorativa. Por sistema, a pobreza económica e a distinção negativa geram e potenciam situações de precariedade socioespacial e habitacional, por um lado, e, por outro, condicionam e/ou reduzem a margem de manobra dos vários actores que procuram inverter a tendência em benefício das comunidades afectadas. Sobre este tópico, Lefebvre $(2009 ; 2000)$ versou sobre a (re)produção do espaço desigual para a (re)produção de capital e, mais tarde reforçado por Harvey (2008), lançou como horizonte de esperança o conceito estruturante do direito à cidade. Apro- contexto do Programa Especial de Realojamento nas Áreas Metropolitanas de Lisboa e do Porto (PER, de 1993) ${ }^{9}$; e (3) o despejo forçado de habitantes de parcos recursos a viver precariamente em terrenos alheios. O cruzamento destes três paradigmas, suas especificidades e efeitos nefastos tem estimulado mobilizações sociais de reivindicação de direitos, de luta e contra-intervenção crítica, tendencialmente apontada para a construção colectiva de uma sociedade e uma cidade mais inclusiva.

A renovação e reabilitação do centro de Lisboa, em curso, está associada a dinâmicas de gentrificação, turistificação ${ }^{10}$ e captação de capital estrangeiro ${ }^{11}$. O paradigma tem provocado o aumento do valor das rendas e de venda de habitação. Sobre o arrendamento, a lei de $2012^{12}$ potenciou, por um lado, esse acréscimo e a atualização dos contratos e, por outro lado, a sua rescisão, dando origem a ordens de despejo. No primeiro caso, muitos arrendatários não têm capacidade de pagar as rendas actualizadas. O segundo caso é motivado pelas lucra- 
tivas oportunidades de venda e/ou transformação dos imóveis em alojamentos locais ${ }^{13}$, com preços diários elevados e com baixa tributação fiscal. São exemplos mediatizados os edifícios da seguradora Fidelidade, em Santo António de Cavaleiros (Loures), adquirida pelo grupo de investimento chinês Fosun, onde 150 famílias foram despejadas para venda dos imóveis; e do prédio na Rua dos Lagares (Mouraria, Lisboa), onde 16 famílias enfrentaram ordens de despejo após venda do edifício para transformação em alojamento local. Aqui, o município conseguiu negociar com o investidor a permanência de todos os visados. Ao mesmo tempo, a retoma progressiva de empréstimos bancários em dita pós-crise financeira, com prestações mensais inferiores às praticadas em arrendamento ${ }^{14}$, tem incentivado as compras $^{15}$. No entanto, muitos não têm capacidade de as realizar ${ }^{16}$. Estas dinâmicas têm empurrado a classe média para periferias ou núcleos urbanos confinantes onde os preços geralmente são mais baixos. Consequentemente, as comunidades empobrecidas que aí residem, como as famílias de origem africana, entre outras, tendem a ser expulsas para margens mais distantes, potencialmente mais acessíveis.

O PER, presentemente em fecho, apoiou financeiramente os municípios para erradicarem as muitas barracas existentes em Portugal no final do século passado, especificamente nas Áreas Metropolitanas de Lisboa e do Porto, e para realojarem os seus moradores em habitações de custo controlado. Identificam-se, aqui, dois problemas de imediato: o programa não abrangeu os agregados que se fixaram nos bairros depois do recenseamento de 1993 (com suas actualizações); novas formas de exclusão socioespacial emergiram e agravaram desde a sua publicação. Além disso, apesar da sua alta taxa de execução, 94\%, 2884 famílias permaneceram por realojar (Lusa, 2017, Abril 15) ${ }^{17}$. Destas, 2117 residem na AML. Mais, dado o grande desfasamento temporal, 25 anos, consolidaram-se novas situações de precariedade habitacional, assinaladas no levantamento do IHRU. Neste contexto, o programa PROHABITA de 2004 configurou um remate de pequena escala, abrangendo situações de grave carência habitacional em todo o território nacional. O programa apostou antes na comparticipação das rendas e no financiamento da compra de casa através de empréstimos bonificados, transferindo para o mercado livre grandes benefícios e responsabilidades socioespaciais. Como ocorreu com o PER nos últimos anos, também o PROHABITA teve pouca cobertura orçamental.

Outra face da exclusão habitacional relaciona-se com a demolição das casas e a expulsão dos grupos de poucos recursos, muitos de origem africana ou etnia cigana, a habitar em terrenos de outrem, públicos ou privados, não listados para realojamento e sem criação de alternativas condignas. Na AML, os bairros de Santa Filomena (extinto em 2016) e 6 de Maio (em fim de extinção), situados em locais estratégicos da Amadora, integram o processo municipal de erradicação de bairros degradados no quadro do PER, sendo exemplares pela grandeza da destruição e pelos despejos forçados de que recentemente foram e/ou são alvo (Figura 1 ). No primeiro caso, os terrenos são sobretudo do Villafundo - Fundo Especial de Investimento Imobiliário Fechado. No segundo caso, existe um projecto de urbanização e de edificação preanunciado para os terrenos municipais e privados que ali estavam ocupados. Neste quadro, o papel de grupos críticos como a associação Habita e a plataforma Stop Despejos ${ }^{18}$ tem sido fundamental na denúncia destes e/ou de outros casos relacionados, especialmente junto da comunicação social e da opinião pública. Estas mobilizações reforçam a voz das populações visadas, por vezes logrando abrandar os processos, mas geralmente sem os conseguir travar. Contudo, as suas acções são resistentes e alimentam o debate público em torno das responsabilidades do governo no que se refere à produção de espaços habitacionais infra-estruturados (com acesso à água, electricidade, saneamento, espaços públicos, etc.) e à promoção de formas de inclusão socioespacial para comunidades despejadas, considerando a propriedade.

Figura $1 \triangleright$ Demolições no bairro 6 de Maio (Amadora)

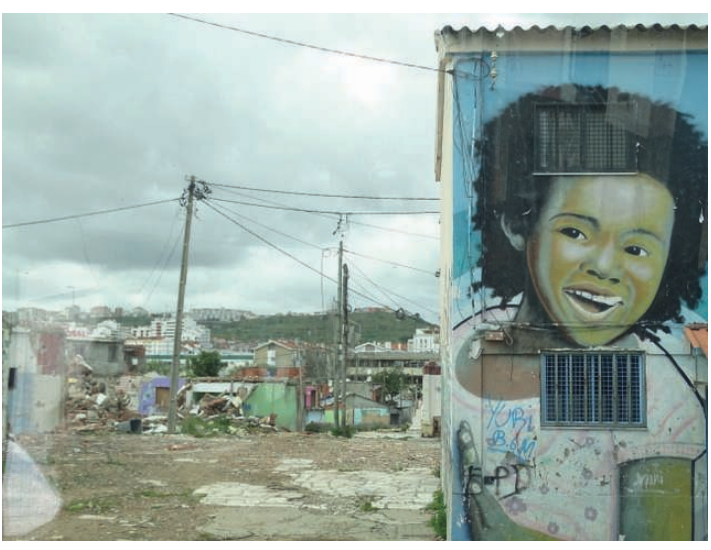

Fonte: Autora (2018)

\section{Paradoxos}

São vários os paradoxos de inclusão-exclusão socioespacial e habitacional, de forte pendor neoliberal, que o governo português tem presentemente de enfrentar. Para perceber os seus significados, tenho necessariamente de situar a Nova Geração de Políticas de Habitação ${ }^{19}$ e o Projecto de Lei de Bases da Habitação ${ }^{20}$, e identificar os actores-chave e as principais forças envolvidas na arena ideológico-política em torno do acesso à habitação, e suas linhas de intervenção. Os processos relacionados 
são intrincados e compreendem conflitos (1) dentro da esfera governamental, (2) entre o governo e as lutas sociais ligadas ao espaço, (3) dentro das mobilizações, e (4) entre grupos críticos, sendo a cooptação dos intervenientes pelo sistema dominante uma divergência fracturante.

A criação de uma Nova Geração de Políticas de Habitação (SEH, 2017) sugere uma estreita articulação de interesses nos ministérios que tutelaram ou actualmente tutelam a Secretaria de Estado da Habitação, produtora do pacote programático: o Ministério do Ambiente e Transição Energética, responsável pela coesão socioterritorial de Portugal, em 2017/2018; o Ministério das Infraestruturas e da Habitação, em 2019. Após consulta pública realizada em 2017, foram aprovados vários instrumentos apontados para o acesso de todos a uma habitação condigna ${ }^{21}$, sobretudo através da criação de incentivos para a reabilitação e o arrendamento a preços ditos acessíveis. Todavia, o valor disponibilizado no Orçamento do Estado de 2018 para a sua implementação foi deveras insuficiente ${ }^{22}$. Acresce que os instrumentos são contraditórios e muito dificilmente lograrão contrariar plenamente os paradigmas de exclusão identificados. Sobre o arrendamento, a desregulação do mercado e a escassez de casas têm proporcionado, por um lado, o aumento excessivo da caução e, por outro lado, a escolha dos arrendatários de acordo com a sua nacionalidade, cor da pele ou duração do contrato, entre outros indicadores discriminatórios. No tocante aos realojamentos, além das 2884 famílias que permanecem por instalar via PER, os municípios identificaram 25762 agregados a precisar de apoio estatal. Os programas anteriores não travaram esta tendência. Agora as novas políticas públicas apostam na descentralização, implicando, no que se refere à população carenciada, a elaboração de Planos Municipais de Estratégia Local de Habitação que identifiquem diversas necessidades. Como ocorreu no levantamento do IHRU, este reconhecimento dependerá dos recursos existentes (humanos, financeiros, etc.), muitas vezes escassos, e de vontades e/ou orientações políticas diferentes, como por exemplo as da Amadora, que tem promovido despejos forçados sem alternativas.

O Projecto de Lei de Bases da Habitação, recém-traçado pelo Grupo Parlamentar do Partido Socialista $(2018)^{23}$, foi submetido a consulta pública e propõe genericamente (1) a requisição temporária de habitações devolutas, (2) a fixação de rendas e (3) a atribuição de subsídios de arrendamento. Este quadro jurídico advoga a construção de estratégias municipais de habitação que definam limites para actividades conflituantes com o acesso à habitação permanente e afirma o papel das juntas de freguesia no reconhecimento de carências graves e recursos existentes. Isto cruza-se com o tema das casas vazias, expectantes de negócio e lucro, menos vívido ao nível do pequeno proprietário, porém com grandes implicações à escala dos fundos imobiliários internacionais. Quanto aos edifícios devolutos do Estado, foi criado um Fundo Nacional de Reabilitação do Edificado ${ }^{24}$, apontado para a habitação com rendas acessíveis. Contudo, os diplomas relacionados com arrendamento e tributação imobiliária não foram a votação no hemiciclo por falta de consenso partidário, logo não foram aprovados a tempo de caber no Orçamento do Estado de 201925. Em contratempo, agudizam-se as forças contrárias do sistema dominante, reforçando os seus paradoxos. Recordo, por exemplo, o leilão de casas efectuado ao abrigo do Programa Renda Acessível, promovido pela Câmara Municipal de Lisboa e a empresa municipal Sociedade de Reabilitação Urbana (Lisboa Ocidental), onde um apartamento de tipologia T1 foi atribuído por $€ 760$, um valor muito acima do limite estipulado para as maiores tipologias (€450) (Lança, 2018). O procedimento foi criticado e, entretanto, anulado.

Em Portugal, sobretudo na $A M L$, as resistências e lutas pelo direito ao lugar e habitação são crescentes. Por um lado, os grupos de parcos recursos, muitas vezes representados por minorias culturais e étnicas, tendem a ser despejados. E, quando são realojados, em alguns casos são confrontados com novas formas de exclusão, por exemplo o seu afastamento para as margens urbanas. Por outro lado, muita classe média não consegue renovar os seus contratos, vendo-se inibida do acesso à habitação, sobretudo no centro urbano. Neste contexto, sendo produto da mobilização social de vários actores, com reverberação mediática e na esfera parlamentar transpartidária (Figura 2), foram ultimamente aprovados dois instrumentos políticos relevantes: o regime extraordinário para o abastecimento provisório de energia eléctrica às habitações precárias que abrangem famílias em situação económica e social vulnerável ${ }^{26}$, por exemplo no bairro da Torre (Camarate, Loures), não concretizado à data; e uma suspensão provisória dos despejos dos arrendatários idosos ou deficientes a viver numa casa há mais de 15 anos $^{27}$, entretanto tornada definitiva. Estes diplomas foram alvo de relutância por parte, respectivamente, da EDP e de uma miríade de proprietários. Em termos úteis, são as comunidades lesadas que motivam as mobilizações que sustentam resoluções políticas que, respondendo a urgências, revertem em seu benefício. Em paralelo ou, pontualmente, em conjunto, induzem ou operacionalizam resistências que, em última análise, se traduzem em ganhos desequilibrados conforme os estratos socioeconómicos envolvidos. Aqui o grande paradoxo reside no facto de os proveitos da classe média não contribuírem, necessariamente, para o aumento equitativo dos recursos dos grupos carenciados, sequer proporcional, mantendo-se e 
reproduzindo-se o fosso socioeconómico, espacial e habitacional, etc., intrínseco ao sistema hegemónico capitalista e neoliberal.

Figura $2 \triangleright$ Visita do Grupo [parlamentar multipartidário] de Trabalho da Habitação, Reabilitação Urbana e Políticas de Cidade ao bairro da Torre (Camarate), 18/07/2017

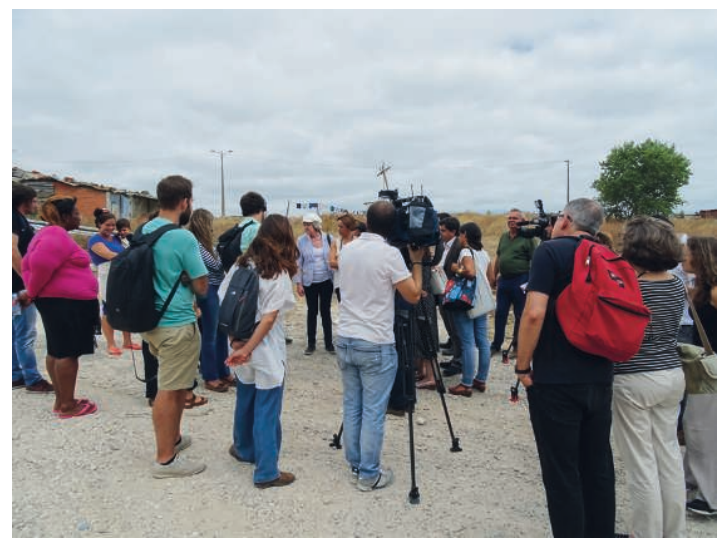

Fonte: Autora (2017).

\section{Teorizando factos}

Esta teorização sobre paradigmas de exclusão baseia-se na reflexão de Foucault (2008) sobre a governamentalidade, ou seja, a forma como o governo procura incluir os seus cidadãos, envolvendo-os em acções apontadas para a manutenção e reprodução das suas próprias lógicas (neste caso de mercado), normalizando-os para que estes cumpram melhor as suas políticas. Também se baseia no ideário ficcionado de tolerância multicultural, como identificado por Žižek (1997), uma abordagem etnocêntrica e condescendente muito favorável à emergência do fundamentalismo e da xenofobia. Contudo, é no pensamento estruturante de Lefebvre (2000) que sustento a minha reflexão sobre produção do espaço político, de modo geral excludente, movida pelo forte valor de troca, simultaneamente espaço físico e prática espacial. E que descodifico o significado do acesso a múltiplos direitos (como à habitação, infra-estruturas, benefícios urbanos, etc.), sendo que a sua soma não resulta na construção duma plena cidadania, sequer no sistema participado e de apropriação colectiva (do espaço e poder) inerente à ideia-chave de direito à cidade, aqui bem sintetizado por Harvey (2008, p. 23): constitui-se como "um direito coletivo e não um direito individual, já que mudar a cidade depende, inevitavelmente, do exercício de um poder coletivo sobre os processos de urbanização"28.

Os paradigmas de exclusão socioespacial e habitacional apresentados apontam para uma diversidade de situações que condicionam ou (re) definem a sociedade urbana em Portugal, sobretudo na AML. Incluem os tópicos da habitação orientada para o mercado, de promoção pública e de constrangimento do acesso à habitação condigna. No primeiro caso, renovação e reabilitação do centro urbano, o mercado cria os mecanismos de que depois se alimenta para reproduzir o capital e o mesmo sistema excludente que o gera, reforçando a teoria de Foucault (2008). No caso do PER, a ideia de regularização e de controlo prevalece (ibid.), sendo que a inclusão de comunidades empobrecidas, de diferentes origens e etnias, (1) não se efectivou plenamente, (2) ocorreu num universo geográfico-temporal específico e (3) potenciou novas situações de exclusão, sincrónicas com outras tantas, reproduzindo dinâmicas de tolerância multicultural (Žižek, 1997). Já através do PROHABITA, o Estado passou para as dinâmicas de mercado o ónus da exclusão, espelhada nos espaços desiguais, mais ou menos centrais ou periféricos, e mais ou menos urbanizados ou precários, conforme a economia dos habitantes (Lefebvre, 2000). Na terceira situação, com a expulsão de populações, sem direito ao lugar ou compensações, estas noções teóricas cruzam-se e reforçam-se, afastando-se mais do direito à cidade (Lefebvre, 2009; Harvey, 2008), orientando o meu olhar para lógicas paradoxais de inclusão-exclusão.

Teorizando agora sobre os paradoxos de inclusão-exclusão socioespacial e habitacional, evoco novamente Foucault (2008) e o conceito de governamentalidade. A ideia captura um processo contraditório - a inclusão como forma de exclusão (ou rumo para) -, implicando uma maior vigilância e controlo do Estado sobre o comportamento da sociedade. Também retomo a noção apontada de tolerância multicultural (Žižek, 1997, p. 44), sendo que esta, em contexto global neoliberal, remete para uma abordagem etnocêntrica e condescendente, assente numa forma respeitosa de "racismo com distância", para afirmação da sua própria superioridade. A descodificação deste processo deveras paradoxal - aceitação como forma de rejeição desvia o foco da Europa, antes centrado no choque entre culturas, para o conflito existente entre visões antagónicas sobre a coexistência de diferentes culturas (Žižek, 2016). Quanto a alternativas, Foucault (2008) apela à resistência e à contra-conduta da sociedade, tendo em conta o seu autoconhecimento para protecção das suas necessidades colectivas, enquanto Žižek (2016) advoga o compromisso da solidariedade global. Nessa senda, Harvey (2000) propõe o uso útil das inconsistências do sistema, visando a construção de uma sociedade emancipada e mais justa. Referente a intervenções e à sua materialidade, Lefebvre (2000) introduz a noção de produção social do espaço social, de representação, tendencialmente mais inclusivo, tendo em conta o seu valor de uso. 
O reconhecimento de alguns paradoxos de inclusão-exclusão socioespacial e habitacional em Portugal remete para as contradições e/ou conflitos latentes ou expressivos entre os vários intervenientes na defesa do acesso à casa, por todos e para todos, e seus efeitos. Esta agnição abrange questões derivadas de estratégias, políticas e instrumentos programáticos e legais, promovidos pelo governo, no entanto motivados por dinâmicas de resistência, posteriormente sujeitos a consulta pública. Nesta situação, os mecanismos produzidos ou em esboço estão orientados para o controlo estatal das comunidades e suas dinâmicas habitacionais, e para a regulação dentro do sistema económico vigente, robustecendo as dinâmicas de governamentalidade sinalizadas por Foucault (2008). Também seguem a senda da tolerância multicultural (Žižek, 1997), quando assumem a inclusão de classes mais vulneráveis e desfavorecidas, e seus diversos constituintes, através do reconhecimento da coexistência da diferença. Além do mais, as recentes respostas públicas às resistências advogam a defesa da sociedade e das suas necessidades colectivas, sendo esta uma dinâmica instigada por Foucault (2008). Porém, essas contra-condutas só ocorrem quando perfilhadas por mobilizações sociais engajadas em torno de uma solidariedade global (Žižek, 2016). Relativamente aos processos habitacionais, a questão central reside no conflito inerente à defesa do valor de uso, próprio da produção do espaço social, na linha de Lefebvre (2000), pela mesma governação que reproduz o sistema neoliberal e, consequentemente, as suas lógicas de exclusão. Paradoxalmente, assumindo a leitura de Harvey (2000), são estas inconsistências que, per se, potenciam a emancipação de uma sociedade mais justa.

\section{Tendências}

Estas notas reflexivas resultam do cruzamento empírico-teórico em torno dos paradigmas e paradoxos de inclusão-exclusão socioespacial e habitacional em Portugal e procuram contribuir para apurar se, neste quadro, todos defendem e/ /ou promovem o acesso à casa, e se todos os beneficiários são contemplados pelas novas dinâmicas ditas inclusivas. O propósito é situar processos complexos e muito expressivos como os da AML e enquadrar o actual contexto económico, político e socioespacial encontrado pelas novas vagas de migrantes vulneráveis e refugiados. Os paradigmas mais recorrentes são a renovação e a reabilitação do centro, alguns realojamentos e despejos forçados. Os paradoxos contemporâneos decorrem de políticas governamentais e de práticas de resistência e luta em função do público-alvo. Os níveis identificados estratégias, políticas, instrumentos e práticas - são descodificados através da lente conceptual provida pelos autores teóricos seleccionados, após enqua- drados no que se refere a leituras discriminatórias do "outro", tendo em conta factores económicos e sociais. Ao mesmo tempo, procuro responder às questões introdutórias relacionadas com o sistema neoliberal e governativo.

Qual a margem de manobra da actual governação nacional para contrariar as linhas sistémicas excludentes da conjuntura neoliberal dominante? O sistema capitalista alimenta-se das crises globais que o constituem, reforçando-o, originando carências financeiras e de acesso aos mais variados direitos, como à habitação. Na AML, a discrepância entre rendimento das famílias e os preços de aquisição de casa é um exemplo expressivo desta situação. 0 aumento do valor das rendas configura outra face da questão, originando despejos. Estas dinâmicas cruzam-se com processos de realojamento e passagens de responsabilidades para os mercados, estando na origem de situações de periferização e exclusão socioespacial, principalmente das comunidades mais carenciadas. A situação agrava-se quando a produção da habitação e espaço habitacional, na acepção de Lefebvre (2000), colide com o direito à propriedade privada. Porém, recentemente, emergiu no quadro governativo português uma força política que afirma estar empenhada na promoção do acesso à habitação adequada para todos. Foram aprovados múltiplos instrumentos, estando em discussão parlamentar outros ligados, sobretudo, à reabilitação urbana e ao arrendamento acessível. Todavia, seguindo Foucault (2008), os mecanismos de inclusão recém-criados são paradoxais e não contrariam plenamente a conjuntura dominante na origem dos processos excludentes em curso. Acresce que a margem de manobra da governação fica condicionada pela fraca afectação de recursos para a sua implementação, sendo esta recusa apoiada pelas forças ideológicas, económicas, estratégicas e políticas contrárias.

Qual a capacidade, no curto período legislativo, de criar mecanismos de inclusão habitacional para os grupos sociais de médios e de poucos recursos com repercussão positiva a médio e longo prazo? Ainda que as forças se alinhem no sentido de viabilizar as medidas ratificadas ou em esboço, a proposta estatal do acesso à habitação para todos reforça o sistema existente e suas contradições, ainda na senda de Foucault (2008). Recordo o transvio neoliberal do leilão do Programa Renda Acessível, da Câmara Municipal de Lisboa, uma ofensiva que pode ser reinventada na municipalização das políticas de habitação. Mesmo assim, no actual período governativo - 4 anos -, a discussão e produção de vários programas e diplomas no quadro específico da Nova Geração de Políticas de Habitação suporta a narrativa pública de "boas intenções e regras" apontadas para o acesso à habitação. Neste âmbito, o governo promove a auscultação pública como abordagem metodológica. Trata-se de um processo 
que afirma na produção do espaço político, tendencialmente excludente, porque com elevado valor de troca (Lefebvre, 2000), o carimbo do exercício de um (muito pequeno e sectário) poder colectivo construído na, e pela, luta pelo direito ao lugar e à habitação. No entanto, o quadro é bastante burocratizado e não responde de forma satisfatória às lutas habitacionais da sociedade civil resistente e das comunidades que representa. A dinâmica não reverte expressivamente para a igualdade de oportunidades e recursos das comunidades e não concorre para a construção do direito à cidade, sabendo as limitações que impõe à participação e apropriação do espaço, defendidas por Lefebvre (2009) e Harvey (2008). Mas reconhece a importância do acesso a múltiplos direitos (à habitação, infra-estruturas, benefícios urbanos) sem, contudo, os garantir, configurando mais um paradoxo de inclusão-exclusão socioespacial e habitacional e, também, da fabricação da própria cidadania.

De que forma a discriminação do "outro", migrante, condiciona o seu acesso à habitação e ao espaço habitacional, mesmo em cenários ditos apontados para a igualdade socioespacial? A captação de capital estrangeiro encontra-se associada ao paradigma da renovação e reabilitação dos centros urbanos, como o de Lisboa. Envolve processos de gentrificação e periferização que, contraditoriamente, penalizam a classe média e as classes mais carenciadas. Em simultâneo, em situação de despejo, em realojamento e expulsão forçada, as comunidades carenciadas, multiculturais e multi-étnicas, tendem a ser precarizadas. A mobilização social dos actores envolvidos na resistência e na luta pelo direito à habitação e ao habitar condigno influenciou regimes extraordinários como o abastecimento provisório de energia eléctrica em habitações precárias de comunidades empobrecidas a viver em terrenos alheios nas periferias das cidades, ainda não efectivado. Nada que se assemelhe à possibilidade de habitar em casa própria e/ou arrendada no centro, junto dos benefícios da urbanização sublinhados por Lefebvre (2009). A diferenciação paradoxal da aceitação do "outro" como exercício de rejeição, na linha de Žižek (1997), ganha assim forma, materializando-se a coexistência etnocêntrica e condescendente entre diferentes estratos socioeconómicos e culturais. Acresce que é, também, pela coabitação de dois actores em representação de forças polarizadas, investidor estrangeiro versus migrante empobrecido, que ocorrem os processos que estão na origem do que Žižek (1997) define como distância de superioridade.

\section{Conclusão}

Em Portugal, nem todos defendem o acesso à habitação e ao espaço habitacional para todos, nem sequer o promovem. Pelo contrário, são múltiplas as forças dominantes que se opõem a esta dinâmica resistente. Simultaneamente, os benefícios alcançados ou na forja estão estratificados de acordo com diferentes níveis socioeconómicos e culturais, proporcionando níveis distintos de inclusão. Estes processos, reprodutores de desigualdades, são visíveis sobretudo na $A M L$, e tendem a excluir situações de choque entre o direito ao lugar e à propriedade. Aqui, em situação de despejo, paradoxalmente, as lutas comuns são mais fortes, todavia com menos resultados. Isto ocorre porque a posse sustenta a mercantilização da propriedade, permitindo a reprodução do capital. Razão também pela qual, no actual quadro neoliberal, os interesses financeiros dos senhorios tendem a ser privilegiados. No entanto, os ensaios conduzidos pela Nova Geração de Políticas de Habitação podem reverter positivamente para a inclusão habitacional dos refugiados e migrantes vulneráveis em Portugal, tendo em conta que configuram uma reforma pública que - alegadamente - visa responder (1) a uma luta socioespacial conjunta, (2) a dinâmicas de consulta pública, e (3) a questões de segregação e periferização nos grande núcleos urbanos, tendo como amplo foco a construção da cidadania. Quanto à miríade de paradoxos identificados, verifico que estes, tal como as crises sistémicas, configuram uma faceta estruturante do sistema neoliberal em curso que, mesmo questionando-o, também o fortalece. Neste quadro, os ecos positivos de esperança das novas políticas do governo são, per se, paradoxais, sugerindo que o tal horizonte de esperança que constitui o Direito à Cidade se encontra fora do modo de produção capitalista e sobretudo aí se poderá forjar.

\section{Notas}

1 Pós-doutoramento em curso no CES-UC com financiamento da FCT (2017/2023) - INSEhRE21. Inclusão sócio-espacial e habitacional dos refugiados na Europa de hoje: Lições da diáspora africana em Portugal.

2 2,821 milhões de um total de 10,256 milhões de pessoas (Área Metropolitana de Lisboa, s.d.; Pordata, s.d.a).

3 A coligação parlamentar de esquerda apoiante do governo socialista em funções desde 2015.

4 Portugal recebeu 1674 refugiados entre finais de 2015 e início de 2018 (PAR, 2018).

${ }^{5}$ O trabalho jornalístico de Henriques (2018a) tem mediatizado o assunto.

${ }^{6}$ A média nacional é $896 € / \mathrm{m}^{2}$ (INE, 2017a).

7 A versão mais recente da Lei da Nacionalidade alargou o acesso à nacionalidade originária e à naturalização às pessoas nascidas em território português: Lei Orgânica n. ${ }^{\circ}$ 2/2018, de 5 de Julho. DR 128/2018, Série I. Lisboa: Assembleia da República.

8 Como nos censos, onde não há consenso sobre o assunto (Henriques, 2018b). 
9 Decreto-Lei n.o 163/1993, de 7 de Maio. DR 106/1993, Série $I-A$. Lisboa: Ministério das Obras Públicas, Transportes e Comunicações.

10 Barata-Salgueiro, Mendes e Guimarães (2017) tratam o assunto.

11 Por exemplo, atribuindo vistos Gold a não-membros da União Europeia em caso de investimento superior a $€ 500000$.

12 Lei n. 0 31/2012, de 14 de Agosto. DR 157/2012, Série I. Lisboa: Assembleia da República. Promovida pela coligação governamental de centro-direita PSD/CDS-PP (2011-2015).

13 Aprovado pelo Decreto-Lei n. ${ }^{\circ}$ 128/2014, de 29 de Agosto. DR 166/2014, Série I. Lisboa: Ministério da Economia. Recentemente foi criado um regime de suspensão de novos registos em áreas centrais da capital (JN, 2018).

14 Alugar um apartamento de $100 \mathrm{~m}^{2}$ em Lisboa custa sensivelmente $1000 € /$ mês. Comprar o mesmo imóvel custa cerca de €223 100 (INE, 2017b). A prestação mensal correspondente é de $€ 665$, segundo simulação no portal Idealista (Idealista: simulador do crédito à habitação, s.d.) para um empréstimo bancário de $80 \%$ do valor total, com pagamento a 30 anos e uma taxa de juro de $2 \%$.

15 A AML teve o maior crescimento do valor de venda (26,4\%) no segundo trimestre de 2017 (INE, 2017c).

16 A plataforma de simulação de crédito à habitação Compara.Já afirma que sensivelmente $40 \%$ dos seus 6000 utilizadores não conseguiria pagar a prestação mensal (Lusa, 2017. Outubro 29).

17 Foram recenseadas 48416 famílias das quais mais de 33 mil residiam na AML (Lusa, 2017. Abril 15).

18 A plataforma Stop Despejos foi criada após a extinção do bairro Santa Filomena.

19 Promovida pela secretária de Estado da Habitação, Ana Pinho.

20 O Projecto de Lei n.o 843/XIII é da autoria da deputada Helena Roseta.

21 Programas: 1.0 Direito - Apoio ao Acesso à Habitação, Porta de Entrada, Arrendamento Acessível, Chave na Mão - Mobilidade Habitacional para a Coesão Territorial, Da Habitação ao Habitat; e, também, Taxas autónomas diferenciadas para os arrendamentos habitacionais com contratos de longa duração, e Alterações legislativas ao arrendamento urbano (Portal da Habitação, 2018).

22 O Orçamento do Estado de 2019 prevê $€ 156$ milhões em gastos com políticas de habitação e reabilitação e com a saúde, por exemplo, €10 922,9 milhões (Pinto, 2018a; Campos, 2018)

23 Os partidos que sustentam a maioria governativa junto com o Partido Socialista, Bloco de Esquerda e Partido Comunista Português, também desenvolveram propostas para a Lei de Bases da Habitação.

24 Resolução do Conselho de Ministros n. ${ }^{\circ}$ 48/2016, de 1 de Setembro. DR 168/2016, Série I. Lisboa: Presidência do Conselho de Ministros.

25 Levando à saída de Helena Roseta do Grupo [parlamentar multipartidário] de Trabalho da Habitação, Reabilitação Urbana e Políticas de Cidade. A deputada entretanto propôs a criação de uma Autoridade Nacional para a Habitação (Pinto, 2018b).
26 Decreto-Lei n.o 36/2018, de 22 de Maio. DR 98/2018, Série $I$. Lisboa: Presidência do Conselho de Ministros.

27 Lei n. 0 30/2018, de 16 de julho. DR 135/2018, Série $I$. Lisboa: Assembleia da República.

28 Tradução livre do original, pela autora.

\section{Referências bibliográficas}

Área Metropolitana de Lisboa (s. d.). Disponível em https://www.aml.pt/index.php

Barata-Salgueiro, T., Mendes, L., \& Guimarães, L. (2017). Tourism and urban changes. Lessons from Lisbon. In $\mathrm{M}$. Gravari-Barbas \& S. Guinand (Eds.), Tourism and gentrification in contemporary metropolises. International perspectives (pp. 255-275). Londres: Routledge.

Câmara de Lisboa aprova restrições ao alojamento local Jornal de Notícias, 25 de outubro de 2018. Retirado de https://www.jn.pt/local/noticias/lisboa/lisboa/ interior/camara-de-lisboa-aprova-restricoes-ao-alojamento-local-10088501.html

Campos, A. (2018, Outubro 16). Saúde vai ter mais 523 milhões de euros em 2019. Público. Retirado de https://www.publico.pt/2018/10/16/sociedade/ noticia/ministerio-da-saude-vai-ter-mais-523-milhoes-de-euros-em-2019-1847680

Decreto-Lei n.o 128/2014 de 29 de Agosto. Diário da República 166/2014 - Série I. Lisboa: Ministério da Economia

Decreto-Lei n.o $163 / 1993$ de 7 de Maio. Diário da República 106/1993 - Série I-A. Lisboa: Ministério das Obras Públicas, Transportes e Comunicações.

Decreto-Lei n.o 36/2018 de 22 de Maio. Diário da República 98/2018 - Série I. Lisboa: Presidência do Conselho de Ministros

Decreto-Lei n.o 36/2018 de 22 de Maio. Diário da República 98/2018 - Série I. Lisboa: Presidência do Conselho de Ministros

Foucault, M. (2008). Segurança, território e população. São Paulo: Martins Fontes.

Grupo Parlamentar do Partido Socialista (2018). Projeto de Lei n. 0 843/XIII, Lei de Bases da Habitação. Disponível em https://www.parlamento.pt/ActividadeParlamentar/Paginas/DetalheIniciativa. aspx?BID $=42502$

Harvey, D. (2000). Spaces of hope. Edimburgo: Edinburgh University Press.

Harvey, D. (2008). The right to the city. New Left Review, 53, 23-40. Disponível em http://newleftreview. org/II/53/david-harvey-the-right-to-the-city

Henriques, J. G. (2018a). Racismo à Portuguesa. Disponível em https://acervo.publico.pt/racismo-a-portuguesa

Henriques, J. G. (2018b, Fevereiro 5). Não há consenso para questionar origem étnico-racial no próximo Censos. Público. Retirado de https:// www.publico.pt/2018/02/05/sociedade/noticia/ pergunta-no-censos-sobre-origem-etnicoracial-nao-e-consensual-1802093

Idealista: simulador do crédito habitação (s. d.). Disponível em https://www.idealista.pt/credito-habitacao/simulador-credito 
IHRU (2018). Levantamento nacional das necessidades de realojamento habitacional. Disponível em https://www.portaldahabitacao.pt/opencms/ export/sites/portal/pt/portal/habitacao/levantamento_necessidades_habitacionais/Relatorio_Final_Necessidades_Realojamento.pdf

INE (2017a). Estatísticas de preços da habitação ao nível local. 2.0 Trimestre de 2017. Destaque, informação à comunicação social. Disponível em https:// www.ine.pt/xportal/xmain?xpid=INE\&xpgid=ine destaques\&DESTAQUESdest_boui $=282088726 \& \bar{D}$ ESTAQUESmodo $=2 \&$ xlang $=$ pt

INE (2017b). Estatísticas de rendas da habitação ao nível local. Destaque, informação à comunicação social. 21 de Março. Disponível em https://www. ine.pt/xportal/xmain?xpid=INE\&xpgid=ine destaques\&DESTAQUESdest_boui $=314753314 \&$ DESTAQUESmodo $=2 \& \times$ lang $=p t$

INE (2017c). Índice de preços de habitação. 3.0 trimestre de 2017. Destaque, informação à comunicação social. Disponível em https://www. ine.pt/xportal/xmain?xpid=INE\&xpgid =ine 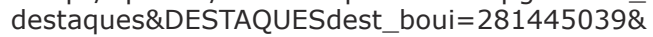 DESTAQUESmodo $=2 \&$ xlang $=$ pt

Lança, F. (2018, Abril 24). Câmara de Lisboa já suspendeu polémico leilão de casas com renda acessível. Jornal de Negócios. Retirado de https://www. jornaldenegocios.pt/economia/rendas/detalhe/ camara-de-lisboa-ja-suspendeu-polemico-leilao-de-casas-com-renda-acessivel

Ledo, W. (2018, Janeiro 31). Comprar casa no Chiado pode custar mais de 10000 euros por metro quadrado. Jornal de Negócios. Retirado de https:// www.jornaldenegocios.pt/empresas/imobiliario/ detalhe/comprar-casa-no-chiado-pode-custar-mais-de-10000-euros-por-metro-quadrado

Lefebvre, H. (2000). La production de l'espace. Paris: Anthropos.

Lefebvre, H. (2009). Le droit à la ville. Paris: Anthropos.

Lei n.o 30/2018 de 16 de julho. Diário da República 135/2018 - Série I. Lisboa: Assembleia da República

Lei n. ${ }^{\circ}$ 31/2012 de 14 de Agosto. Diário da República 157/2012 - Série I. Lisboa: Assembleia da República

Lei Orgânica n. 0 2/2018 de 5 de Julho. Diário da República 128/2018 - Série I. Lisboa: Assembleia da República

Lisboa custa, em média, 3291 euros por metro quadrado. Jornal de Negócios, 23 de outubro de 2017. Retirado de https://www.jornaldenegocios.pt/ multimedia/infografias/detalhe/lisboa-custa-em-media-3291-euros-por-metro-quadrado

Lusa (2017. Abril 15). Programa Especial de Realojamento tem cerca de 2800 famílias à espera de casa. Público. Disponível em https://www.publico. pt/2017/04/15/sociedade/noticia/programa- -especial-de-realojamento-tem-cerca-de-2800-familias-a-espera-de-casa-1768866

Lusa (2017. Outubro 29). Simulação de crédito habitação indica que $40 \%$ dos portugueses teria dificuldades em pagar. Diário de Notícias. Retirado de https:// www.dn.pt/lusa/interior/simulacao-de-credito-habitacao-indica-que-40-dos-portugueses-teria-dificuldades-em-pagar-8880729.html

Pinto, L. (2018a, Outubro 16). Governo destina 156 milhões a Políticas de Habitação e Reabilitação. Público. Retirado de https://www.publico. pt/2018/10/16/economia/noticia/orcamento-de-estado-destina-156-milhoes-de-euros-a-politicas-de-habitacao-e-reabilitacao-1847718

Pinto, L. (2018b, Novembro 13). Helena Roseta propõe uma Autoridade Nacional para a Habitação. Público. Retirado de https://www.publico.pt/2018/11/13/ economia/noticia/helena-roseta-vai-propor-criacao-autoridade-nacional-habitacao-1850801\#gs. Dvr3Qifi

Plataforma de apoio aos refugiados (2018). Disponível em http://www.refugiados.pt/refugiadosemportugal/

Pordata (s.d.a). BI de Portugal. Disponível em https:// www.pordata.pt/Portugal

Pordata (s.d.b). Rendimento médio das famílias. Disponível em https://www.pordata.pt/Portugal/Ren dimento+médio+disponível+das+famílias-2098

Pordata (s.d.c). Poupança bruta em \% rendimento disponível. Disponível em https://www.pordata. pt/Portugal/Poupança+e+ordenados+salários+ no+total+do+rendimento+disponível+dos+part iculares+(percentagem) -710

Portal da Habitação (2018). NGPH. Disponível em https://www.portaldahabitacao.pt/pt/portal/ habitacao/npgh.html

Resolução do Conselho de Ministros n. 0 48/2016 de 1 de Setembro. Diário da República 168/2016 - Série I. Lisboa: Presidência do Conselho de Ministros

SEF (2016). Relatório de imigração, fronteiras e asilo. Disponível em https://sefstat.sef.pt/Docs/ Rifa2016.pdf

SEH (2017). Para uma Nova Geração de Políticas de Habitação: Sentido estratégico, objetivos e instrumentos de atuação. Disponível em https:// www.portugal.gov.pt/download-ficheiros/ficheiro. aspx?v=95621259-fdd4-4099-82f3-2ff17c522882

Žižek, S. (1997). Multiculturalism, or, the cultural logic of multinational capitalism. New Left Review, $225,28-51$.

Žižek, S. (2016). A Europa à deriva: A verdade sobre a crise dos refugiados e o terrorismo. Lisboa: Objectiva.

Recebido a 31/10/2018. Aceite para publicação a 17/01/2019

Sílvia Leiria Viegas (silviaviegas@ces.uc.pt). Bolseira da Fundação para a Ciência e a Tecnologia (SFRH/ /BPD/118022/2016 - FSE/POCH), investigadora de pós-doutoramento do Núcleo de Estudos sobre Cidades, Culturas e Arquitectura do Centro de Estudos Sociais da Universidade de Coimbra (CCArq/CES-UC) e membro do Grupo de Estudos Sócio-Territoriais, Urbanos e de Ação Local da Faculdade de Arquitectura da Universidade de Lisboa (GESTUAL/FA-UL). Colégio de S. Jerónimo, Largo D. Dinis, Apartado 3087, 3000-995 Coimbra. 